hydrogen and vioe versâ, and by exploding the mixtures and measuring the residual gas the percentage of reverse current can be calculated. By this method I found on using an $x$ ray tube with an equivalent spark-gap of three centimetres and using no valve tube that 15 per cent. of reverse current was passing. And, on the other hanò, by using an efficient valve tube $I$ found that all the reverse current had been suppressed.

New Cavendish-street. W.

\section{THE PROPHYLACTIC USE OF ANTITOXIN IN EPIDEMIC DIPHTHERIA.}

BY EVERITT E. NORTON, M.R.O.S. ENG., D.P.H., \&C., MEDICAL SUPERINTENDENT OF THE ISLEWORTH INFIRMARY.

EARLY in the present year diphtheria appeared in epidemic form at the Percy House (Brentford Union) Schools, which are under the management of the Poor-law guardians and are situated at Isleworth. There also, upon adjoining sites, are the infirmary and workhouse. The schools are residential, consist of various buildings, and accommodate about 300 children. Communication between the children of both sexes and different ages is in the class-rooms, at meal-times and otherwise, free; the older children walk out in small parties under certain restrictions; and the majority of the children are periodically visited by relatives or friends. Admissions and discharges are frequent, all children admitted or readmitted spending (in batches) a probationary period in isolation before mixing with others or attending classes. The schools are often full: thus in November, 1906, they contained 277 children and by the end of December the number had reached 309 . Sick children are treated in the separate infirmary.

Before Christmas the fact had been noted that cases of septic sore-throat and follicular tonsillitis were occurring with a frequency somewhat unusual. During Christmas-time and the few days following the weather was inclement, and necessarily the children were much herded together in crowded, and consequently dusty, day-rooms, the hours spent under these conditions being prolonged by the fact that educational work, which is carried on in a separate building, was suspended. On Sunday, Jan. 6th, 1907, two children who, having sore-throat, had been transferred to the infirmary for observation and treatment were found to be suffering from diphtheria. A rigorous examination of all the school-children revealed suspicious conditions in the throats of a considerable number, and by the end of a week (Jan. 12th) 20 cases of diphtheria had been notified. It was found from the first to be necessary that the throat of every child in the schools should be daily inspected. All children found to be, or suspected of being, infected were isolated. Antitoxin treatment was at once commenced and free use was made of bacteriological examination of swabbings as an aid in diagnosis. The usual means of disinfection, \&c., were stringently adopted with a view to limiting the risk of infection. Arrangements were completed whereby the majority of the children affected were transferred from the infirmary to the local (Mogden) isolation hospital and to the isolation hospitals at Acton and Faling. These methods were steadily persevered in, but nevertheless cases continued to arise, the numbers notified during the weeks ended Jan. 19th, Jan. 26th, Feb. 2nd, and Feb. 9th being respectively 17, 7, 7, and 13 these, with two cases on Feb 10th, making a total to that date of 66 . The persistence of the outbreak and the fact that it affected all classes of children throughout the school proved only too clearly that a widespread infection existed. The board of guardians kindly gave me the opportunity of consultation (on Sunday, Feb. 10th) with Dr. R. Tanner Hewlett, and with his concurrence the use of antitoxin as a prophylactic measure was decided upon. The number of children in the schools was at this time 251. Swabbings from the throats of all were taken and were examined by Mr. H. O. Bousfield, of the Camberwell Research Laboratories. The 16 children from whose throats the specific bacillus or even a suspicious culture had been obtained after cultivation were isolated and were put under treatment with a view to freeing the throats from infection. On either Feb. 11th or 13 th antitoxic serum was administered to every child, it being inconvenient to deal with all upon one day. The dosage was so arranged that the 16 children isolated received each 1000 units and all other children, as well as several members of the adult staff, each 500 units irrespectively of age. These quantities were, I believe, somewhat larger than have usually been adopted for protective purposes. It was thought, however, that, having in view the rarity of ill-effects from the use of serum injections as now prepared and administered, the degree of protection to be afforded should not be minimised by any diffidence. The cbildren were still daily examined and carefully watched. A further case of diphtheria arose on Feb. 21st, another on the 27th, and two on March 2nd.

A second antitoxin injection was administered throughout the school on March 6 th and $8 \mathrm{th}$, the doses being similar to those previously given. No further cases occurred until April 9th when there was one. On April 12th there was another. Two more appeared on May 10th. With those cases the epidemic ended. Eight cases of diphtheria (all showing definite signs and all proved bacteriologically) arose therefore, in different parts of the schools in children who had received the antitoxin treatment, two of these occurring more than two months after the second injection.

With regard to the causation of the outbreak there can be no doubt that diphtheria infection was carried into the schools at a time when conditions were favourable for its development. The arrangements under which the admission of children takes place practically preclude the possibility of a case of active diphtheria being admitted, but no swabbings for bacteriological examination are taken from the throuts of children upon admission or during the period of probation. I have remarked that the early diagnosis of cases was only attained by daily inspection of all the children's throats. At the very commencement of the epidemic it was noticed that it was exceedingly uncommon for the diphtheritic children to make any complaint whatever or to show any symptoms of illness, so that in the great majority of the cases the presence of disease was first detected in the course of the daily examinations. Constitutional symptoms during the period of "invasion" were almost invariably absent and appeared only if, and when, absorption from the throat lesion had commenced.

The results of the daily inspection were very interesting. Getting, as one did, to "know by sight" many abnormal throats, surprising degrees of variation from week to week in their characteristics were not infrequently found. The presence of enlargement of the tonsils, of tonsils with deep crypts, of chronic pharyngitis, or of adenoid growths, did not appear to increase the susceptibility to diphtheritic infection. Some of such conditions, however, and especially the deep tonsillar crypts, seemed to favour the obstinate harbouring of the Klebs-Löffler and Hoffmann's bacilli and of other organisms. As a means of selecting children as especially liable to, or as being in the "incubation period" of, diphtheria naked-eye inspection proved utterly futile. I myself upon one occasion selected some 20 children as having absolntely healthy throats so far as could be observed; within 24 hours two of these had developed patches of membranous deposit upon the tonsils.

The method of daily inspection for the purpose of selecting cases for further examination was necessarily rapid. The children were easily taught to come up in turn each bringing a spoon, the handle of which was used as a tongue depressor. The spoons were thrown as used into pails in which they were subsequently boiled.

The ages of the 74 children who suffered from diphtheria were as follows : 5 were three years of age, 8 four years, 8 five years, 9 six years, 13 were from seven to nine years, 12 from ten to 12 years, and 19 from 13 to 15 years. The cases were usually treated in the first instance in the infirmary and seven remained there throughout. 20 were transferred to Mogden isolation hospital, 34 to Acton isolation hospital, and 13 to Ealing isolation hospital, where they were under the care of $\mathbf{M r}$. Herbert $\mathbf{R}$. Power, Mr. D. J. Thomas, and $\mathrm{Mr}$. Lewis $\mathrm{D}$. Brown respectively, to all of whom I am indebted both for the interest which they took in our little patients and for the information with which they have kindly supplied me. The cases proved generally mild, and I attribute their favourable course partly to the fact that few young infants were included but chiefly to early diagnosis and prompt commencement of antitoxin treatment. The throat was free from membrane in many instances in 24 or 36 hours, and $\mathrm{Mr}$. Thomas remarks that " most of the children were up and about at the end of the second week, an event very rare" in the cases admitted under: his care. 
Complications and sequelæ were uncommon; albuminuria was rare; paralytic symptoms were noted in four cases; in no case was there nasal or laryngeal implication, or was tracheotomy necessary. Two children (both girls aged nine years) died from cardiac dilatation and failure; of these, one was the first case of the series and antitoxin treatment was delayed. Several of the children subsequently developed ulcerations of the tonsils ; these occurred late, during convalescence, and gave rise to some anxiety, but they were found not to be associated with the presence of bacilli, and they yielded rapidly on being carefully painted with liquor iodi. The bacillus remained persistently in many of the throats, more especially in those in which enlarged tonsils or adenoid growths were present. I have remarked that the same effect of these conditions was noticed in children who did not develop diphtheria.

Especial interest attaches to the use made of antitoxin. No other instance is known to me in which it has been sought to immunise by its use so large a number of children. The serum used was that supplied by a well-known firm in phials containing each 2000 Ehrlich-Behring units and was not highly concentrated. In most of the prophy lactic doses the bulk of fluid was sufficiently small to allow of its being given by means of an ordinary hypodermic syringe; the injections were made under the prepared skin of the back below the angle of the scapula, a fresh needle from a supply kept in spirit being used in each case.

Of definite ill-effects following upon the treatment there were none. One girl showed a general urticarial eruption lasting 36 hours after the first injection, but none after the second. One boy had a spreading erythematous blush around the puncture, arising within a few hours of the second injection; this was accompanied by a slight rise of temperature and passed off in two days. The children generally regarded the treatment as a not unpleasant mild form of excitement. It was thought that a slight depression followed and that their play was for a few hours afterwards less noisy. No other effects whatever were noted. There was, of course, no evidence that the treatment had any effect in hastening the elimination of bacilli from the children's throats; much trouble, in fact, was caused by their tenacity.

It has been shown that attempts were made simultaneously to rid the school of infection by isolating all children with infected throats and to render all the children immune by the administration of antitoxin. Had it been supposed that it was feasible by one examination of a swabbing from every child's throat to differentiate the infected antitoxin might not have been used. It is well known, however, that more than one such examination is necessary before freedom from infection can fairly be assumed and multiple examinations before discharge now form part of the accepted routine in most fever hospitals. There was ample evidence that infection was rife amongst the children in Percy House Schools after Feb. 13th ; eight cases of diphtheria actually arose in spite of the protection which was afforded by the treatment adopted and bacteriological proof was abundant that many infected throats were present amongst children other than those who had been isolated. There can, I consider, be no doubt that the arrest of the spread of the epidemic was due to the prophylactic action of antitoxin. Its administration upon so large a scale was not undertaken without serious consideration and it is satisfactory to be able to record that its use appears to have been amply justified by the results attained. Isleworth.

\section{ON THE USE OF A NEW FLUID FOR THE HÆMATOCYTOMETER.}

BY ALEXANDER EDINGTON, M.D EDIN, D.P.H. EDIN. AND GLASG, F.R.S. EDIN.

LATE DIRECTOR OF THE GOVERNMENT BACTERIOLOGICAL INSTITUTE, CAPE COLONY.

WHILE the enumeration of the red and white blood corpuscles as an aid to diagnosis of obscure conditions has been more or less in vogue for more than a quarter of a century, its utility, not only as a diagnostic aid but as indicating alterations under treatment, has only attained the present general acceptance within recent years. But even now the practice of making blood counts is by no means universal. An explanation for this may possibly be found in a want of appreciation of the method by some, want of time in the case of others, or in the undeniable fact that some little dexterity and patience are requisite for obtaining rustworthy results. The last reason is perhaps the most salient and one must admit that the use of even so good an instrument as the Thoma Zeiss hrematocytometer requires dexterity and precision, while accuracy is to some extent impeded by the want of a suitable diluting fluid.

of all the fluids in use-and there are a considerable number-the best that can be said of them is that they make an approach to being isotonic with normal blood. "A solution containing just such a percentage of salt as suffices to keep the corpuscles unaltered in form and without removal of any of their hromoglobin is 'isotonic.' For human blood a solution of common salt is isotonic with 0.9 , for defibrinated ox blood with $0 \cdot 6$, and about the same for frogs' blood. Very slight differences of external condition will tend to alter the permeability of the blood corpuscles both for hæmoglobin and for other substances" (Schäfer's "Textbook of Physiology").

The normal specific gravity of the blood in a healthy subject is from 1058 to 1062 but in departures from the normal the specific gravity may be much lower and has been found even so low as 1033. With a lower gravity the hæmoglobin falls in an almost constant fashion, so that while with a specific gravity of 1057-60 there may be 85 per cent. to 95 per cent. of hæmoglobin, with a specific gravity of 1033-35 the hæmoglobin will have fallen to 25 per cent. to 30 per cent. When coagulation is prevented the corpuscles of drawn blood very soon sink, leaving the yellow plasma as a supernatant fluid, and it is evident that if hæmoglobin is given up by the corpuscles to the plasma it is very soon eliminated from that fluid, most probably ky the kidneys In various kinds of experimental hæmolyses I have found free bæmoglobin in the plasma antecedent to its appearance in the urine. It is probable, therefore, that changes in the amount of bæmoglobin are in great part due to abnormal permeability of the corpuscles and also to their destruction. In any case, supposing the blood to be examined to be that of an abnormal individual, we may assume that the specific gravity is almost certainly below the normal. If this be the case then the use of a fluid which is isotonic for healthy blood is most certainly improperly constituted for a blood of lower specific gravity. It seemed to me, therefore, of some importance to determine whether one could not prepare a fluid which, without having great regard to the isotonic quality, would be useful for any kind of blood.

Some ten years ago I first used neutral citrate of potassium as a means to maintain large quantities of pathological bloods in a fluid condition so that they could be used for inoculation, and the plan I then adopted has, since that date, found its way into most bacteriological institutions. What, however, struck me as remarkable was the fact that the red blood corpuscles maintained their shapes and characters in a marvellous manner, so that even blood films could be made with blood so prepared. I have therefore prepared the following solution for use with the hæmatocytometer: neutral citrate of sodium, $7 \cdot 5$ grammes; formalin ( 40 per cent.), 2.0 cubic centimetres; dahlia (Grübler's), 0.03 grammes; chloroform 5 drops and distilled water, 250 cubic centimetres. In preparing the solution it is better to mix the stain with the water, rubbing down the former with a few drops of the latter first, then to add the citrate and formalin. The solution should be left for a day or two without filtering so as to deposit all the less soluble portions of the dye. The solution is easily made and keeps well when kept in a dark and cool place. If, however, it has not been used for some time it is advisable to filter off a small portion for immediate use. In less than a minute after the diluted blood has been placed on the slide one will find the red corpuscles deposited on the glass so completely that nearly all are in focus, while the refractive index of the corpuscles is so well maintained that they are very easily counted.

In practice I prefer to eject one or two drops from the tube of the hæmatocytometer and thereafter to empty the remainder into a small glass tube which is closed by a wellfitting stopper. By this means the mixed blood and fluid may be sent long distances for examination. Messrs. Thomson, Skinner, and Hamilton, of 38, Sauchiehall-street, Glasgow, now supply such tubes at a nominal cost. The hæmatocytometer tube, after using this solution, is very readily cleaned, a circumstance which may commend itself to many. The rubber tube supplied with the Thoma-Zeiss hæmatocytometer is too short. I prefer using a rubber tube 